\title{
Educating Cancer Prevention Researchers in Emerging Biobehavioral Models: Lessons Learned
}

\author{
Virmarie Correa-Fernández • Marivel Davila • \\ Samira A. Kamrudin • Dennis H. Li • Syed W. Noor • \\ Abiodun O. Oluyomi $\cdot$ Shine Chang $\cdot$ Carrie Cameron
}

Published online: 2 July 2011

(C) Springer Science+Business Media, LLC 2011

\begin{abstract}
To increase the adoption of transdisciplinary research methods among future cancer prevention investigators, faculty members from The University of Texas MD Anderson Cancer Center developed a graduate-level course in biobehavioral methods in cancer prevention research. Two instructors paired by topic and area of expertise offered an hour-long lecture-based seminar every week for 15 weeks during the spring semester of 2010 . Students and presenters both evaluated the overall course
\end{abstract}

Virmarie Correa-Fernández, Marivel Davila, Samira A. Kamrudin, Dennis H. Li, Syed W. Noor, Abiodun O. Oluyomi share primary authorship.

Electronic supplementary material The online version of this article (doi:10.1007/s13187-011-0251-x) contains supplementary material, which is available to authorized users.

\section{Correa-Fernández}

Department of Health Disparities Research,

Division of Cancer Prevention and Population Sciences,

The University of Texas MD Anderson Cancer Center,

Houston, TX, USA

M. Davila $\cdot$ D. H. Li $\cdot$ S. W. Noor

Division of Health Promotion and Behavioral Sciences,

The University of Texas School of Public Health,

Houston, TX, USA

\section{S. A. Kamrudin • A. O. Oluyomi}

Division of Epidemiology, Human Genetics and Environmental

Sciences, The University of Texas School of Public Health,

Houston, TX, USA

\section{S. Chang $\cdot$ C. Cameron $(\bowtie)$}

Department of Epidemiology,

Division of Cancer Prevention and Population Sciences,

The University of Texas MD Anderson Cancer Center,

Cancer Prevention Building 7.3556,

Unit 1340, P.O. Box 301439, Houston, TX, USA

e-mail: ccameron@mdanderson.org content and delivery method, as well as each session. A total of 11 students and 22 presenters participated in the course. In each class session, one presenter was from a behavioral science background,and the other was from a biological sciences background. Both presenters and students expressed overall satisfaction with the content and format of the course. The presentation of topics from a transdisciplinary perspective and interaction with presenters from both biological and behavioral sciences are valuable and can help junior researchers prepare to meet the emerging challenges in cancer prevention research.

Keywords Cancer · Addiction · Biobehavioral · Cancer education $\cdot$ Transdisciplinary

\section{Introduction}

"Health and disease are determined by dynamic interactions among biological, psychological, behavioral, and social factors. Cooperation and interaction of multiple disciplines are necessary for understanding and influencing health and behavior." Institute of Medicine (2001, p. 16)

Since the Institute of Medicine called for increased cooperation among disciplines to identify and target interventions aimed at improving public health [1, 2], researchers studying risk-related behaviors have sought to elucidate the interplay among biological, behavioral, and social determinants of these behaviors. This increasing awareness of the importance of transdisciplinary methods in addressing many of today's most perplexing public health issues has led to the development of research and training initiatives funded by both private foundations and public 
agencies [3-8]. Recently, the Office of Behavioral and Social Sciences Research of the National Institutes of Health (NIH) included four new programmatic directions in its strategic prospectus, including an effort to facilitate collaborative research across disciplines in creating innovative conceptual frameworks, methods, measures, and technologies to improve public health in a timely manner [9]. Tobacco cessation efforts and the landmark NIH Diabetes Prevention Program [9] are examples of successful transdisciplinary advances in research and in improving population health. Relying on the contributions of basic, behavioral, and social sciences, transdisciplinary methods, along with new tools and technologies, have set the stage for a blending of research findings from cellular to societal levels.

Despite this emphasis on transdisciplinary methods as a priority in health science, limited funding opportunities for educational development and a lack of communication across research silos are among the obstacles impeding the growth of training opportunities in biobehavioral methods [10]. Such methods are highly labor intensive, are prone to conflict, and require that participants be prepared and trust one another if the efforts are to be successful [11-13]. Junior researchers who are focused on establishing their individual scientific identity within their field of interest may be concerned that the time involved in conducting transdisciplinary collaborative research will take away from their individual research efforts [14].

There is continuing enthusiasm about the significance of transdisciplinary approaches to cancer prevention [15-17]. Hiatt and Breen [17] noted that "because cancer involves the complete spectrum of scientific endeavor from genes to society, a transdisciplinary research perspective may be the best approach for understanding the complex, multilevel causal mechanisms and pathways needed to inform cancer control interventions and policies" (p. S143). In an attempt to increase the adoption of transdisciplinary research methods among future cancer prevention investigators, faculty members from the Division of Cancer Prevention and Population Sciences (DCPPS) at The University of Texas MD Anderson Cancer Center, along with external consultants, directed the development of a 1-h, pass/fail, graduate-level pilot course in biobehavioral methods in cancer prevention research for the spring 2010 semester. Course directors sought to provide students with an overview of innovative methodologies in biobehavioral research and of the complex interplay of genetic, neurobiological, and environmental factors in cancer prevention and addiction.

This article describes the development, structure, and evaluation of this innovative biobehavioral approach to graduate cancer education. This course can serve as a model for other educators interested in biobehavioral approaches to education. The description provided here will contribute to the literature, stimulate educators to develop similar courses, and ultimately enhance the way junior researchers are currently trained.

\section{Course Development}

This graduate-level course was one of several ideas proposed during the process of applying for the renewal of a 5-year National Cancer Institute-funded Cancer Education Grant (R25E), which requires innovations in cancer education curriculum development and dissemination. The principal investigators on the grant, hereafter referred to as "course directors," determined that transdisciplinary research training was scarce at both the local institution and elsewhere and decided to develop a course to meet the requirement. Course directors formed a multidisciplinary subcommittee from the Advisory Committee of the DCPPS that included faculty from various institutions in the Texas Medical Center (TMC; mainly MD Anderson and Baylor College of Medicine (BCM)) and recognized expert consultants in biobehavioral approaches in cancer prevention and obesity research from The University of Alabama at Birmingham and Uniformed Services University of the Health Sciences. Additional members were added over time at the recommendation of members from the Advisory Committee.

Encompassing a wide range of research and expertise in cancer prevention and addiction, the subcommittee determined the format and curriculum of the course. From an initial selection of course topics, the subcommittee compiled a list of potential presenters based on established expertise and references from other experts. Presenters from the TMC and the greater Houston area were given priority because of limited resources and the goal of sustaining the course. Invited presenters provided formal indication of their interest in participating, and these were reviewed by the Curriculum Approval Committee of The University of Texas Graduate School of Biomedical Sciences (GSBS), the accredited academic arm of MD Anderson.

The course directors paired most presenters by topic according to their areas of expertise, generally placing experts from biological science backgrounds with experts from behavioral science backgrounds. In many cases, the presenter pairs did not know each other, so the course directors went through a "matchmaking" process of providing presenter pairs with internet links to each other's descriptions and curriculum vitae, the course syllabus, and working titles of both presentations. Presenters were invited to revise the proposed titles and identify supplementary readings for their lectures. 
The course syllabus and the list of participating presenters were submitted for approval to the Curriculum Approval Committee at GSBS. Given the fact that important risk behaviors for cancer are addictive, the committee suggested adding "Addiction" to the original title, Biobehavioral Research Methods in Cancer Prevention, resulting in the final title of Biobehavioral Research Methods in Cancer Prevention and Addiction. The course directors also worked with The University of Texas School of Public Health (SPH) Curriculum Approval Committee to submit the course for cross-listing at the SPH. Upon approval, the course was advertised to students at the GSBS and SPH and elsewhere in the TMC through electronic announcements, emails, and flyers. Program heads and school registrars were provided information about the course and encouraged to promote the course to their constituents. The course was offered for one credit hour or for audit, and students registered for the course through either the GSBS or SPH.

The objectives of the course were for students to be able to (1) define biobehavioral research and identify issues that help and hinder the success of such research; (2) indicate the areas of intersection between behavioral and basic science research; (3) provide examples of successful applications of biobehavioral research methods in cancer prevention and addiction; and (4) suggest health conditions and research topics in health science that might benefit from biobehavioral research approaches. The course focused on emerging areas of research in tobacco, alcohol, and drug use; physical activity; diet; stress; and alternative medicine conducted at several institutions, including MD Anderson and $\mathrm{BCM}$.

\section{Course Structure}

Classes were lecture-based seminars during which students could interact with the presenters. Classroom scheduling was managed by MD Anderson administrators, and each classroom consistently had a roundtable setup to facilitate discussion. During the first class, students were provided an overview of the course and introduced to the biobehavioral concept. Each class thereafter was devoted to a specific topic, and the time was divided between the two presenters. Usually, the first presenter provided a general and/or biological overview of the topic, and the second presenter focused more on behavioral aspects. The last class was devoted to synthesizing the class content and discussing the applicability of the methods presented throughout the course.

The course syllabus comprised a total of 15 sessions (Fig. 1). The presenters were 22 junior and senior faculty (including course directors), each a specialist in the topic on which he/she was invited to speak. Approximately half represented the behavioral sciences, and the other half represented the biological sciences. The majority of the classes $(67 \%)$ were facilitated by two presenters, and only one presenter participated in more than one class by giving two different lectures. Some of the paired presenters had been collaborators for years, and their joint presentation was an extension and example of their teamwork; others had neither worked together before nor coordinated their presentations in advance and just divided the time upon arriving at their scheduled class. Course directors observed that senior faculty more frequently inquired about students' backgrounds before starting their presentations than junior faculty, many of whom began their presentations without much introduction.

All presenters used Microsoft PowerPoint, and copies of the slides were provided to students before each class. Lectures were recorded using Camtasia Studio software v6.0.3 (TechSmith, Okemos, MI) and made available to students after each class. Students also received hard copies of supplementary readings for the upcoming class. Electronic copies of all materials were housed on MD Anderson's online Sakai course management system. Attendance was mandatory, but students who missed could make up an absence by watching a recording of the class and writing three quiz questions and answers about the material. The setting of the classes was intimate and casual, and students were encouraged to ask questions and discuss.

Eleven students of diverse ethnic backgrounds enrolled in the class, six of whom took it for credit. Most students were men $(55 \%)$, older than traditional graduate students ( $\geq 32$ years), and enrolled in either doctoral or postdoctoral studies. Students' disciplines included behavioral sciences (e.g., psychology, health promotion), epidemiology, and pediatric nutrition. More than half heard about the course through promotional emails, although a few learned about it through posted flyers or by word of mouth. Most of the students reported that they enrolled in the course because they wanted to increase their knowledge and/or skills in biobehavioral research methods. In addition, about half of them (45\%) identified cancer as a specific topic of interest. All students reported becoming researchers and entering academia as career goals. Students reported their demographics, disciplines, reasons for enrolling, and other information on a short form provided during the course.

\section{Evaluation}

Students' Evaluations

Session Evaluations At the end of each class session, students completed a ten-item four-point Likert scale $(1=$ 


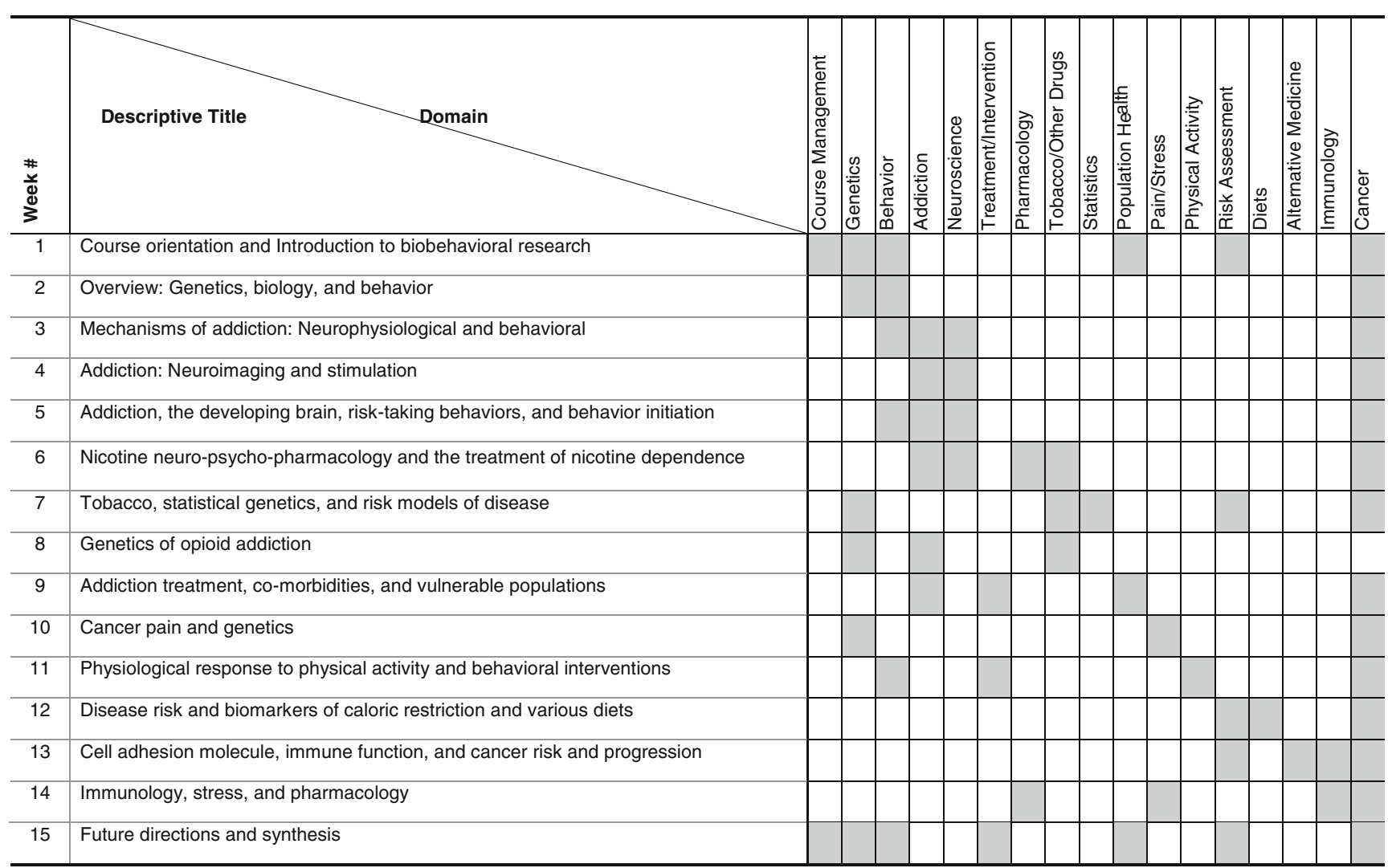

Fig. 1 Course syllabus and respective domains

strongly disagree through 4=strongly agree) evaluation instrument (Appendix A) for each presenter on the organization and structure of the lecture and the presenter's teaching skills. Additional space was provided for written comments. The total number of evaluation surveys (TES) that was completed by students over the course of the semester was 219. TES $=\sum_{i=1}^{n}\left(\mathrm{SN}_{\mathrm{P}} \times \mathrm{SN}_{\mathrm{AS}}\right)$, where $i$ represents class sessions from 1 (first class session) through $n$ (last session for which presenter evaluations were conducted), $\mathrm{SN}_{\mathrm{P}}$ is the number of presenters at any particular session, and $\mathrm{SN}_{\mathrm{AS}}$ is the number of students in attendance at the session. Descriptive analyses of quantitative evaluation data were performed using PASW Statistics, v.17 (SPSS Inc., 2009, Chicago, IL). Most students strongly agreed that the course organization and structure, as well as the instructors' teaching skills, were adequate. The evaluations revealed a high level of satisfaction with the instructors' performances and minimum variability across instructor ratings (Fig. 2).

Mid-Semester Feedback Midway through the semester, part of a class session was used to provide open feedback on the content and implementation of the course so far. Course directors led discussions on students' satisfaction with the course and how it could be improved. Students' comments about the course, collected via an informal qualitative method, were summarized into three categories: (a) didactic experience, (b) content, and (c) overall logistics.

Didactic Experience By and large, students reported that the learning objectives for the course were met. They emphasized that the learning environment was a positive aspect of the course because, in contrast to typical seminars, they felt free to make comments, ask questions, and reveal a lack of knowledge about certain topics. Students also considered having two presenters from different backgrounds and expertise highly valuable because their interaction in class exemplified transdisciplinary work. Students highlighted the description of the presenters' research paths as an asset of the didactic experience because it helped the students understand how to translate ideas into concrete investigations and, subsequently, into practice and intervention. Students suggested that presenters should be provided with specific guidelines on how to focus their presentations, particularly from a transdisciplinary standpoint.

Content Students highlighted the knowledge they acquired regarding the complex interplay between behavioral and biological factors that influence the risk of disease (e.g., 


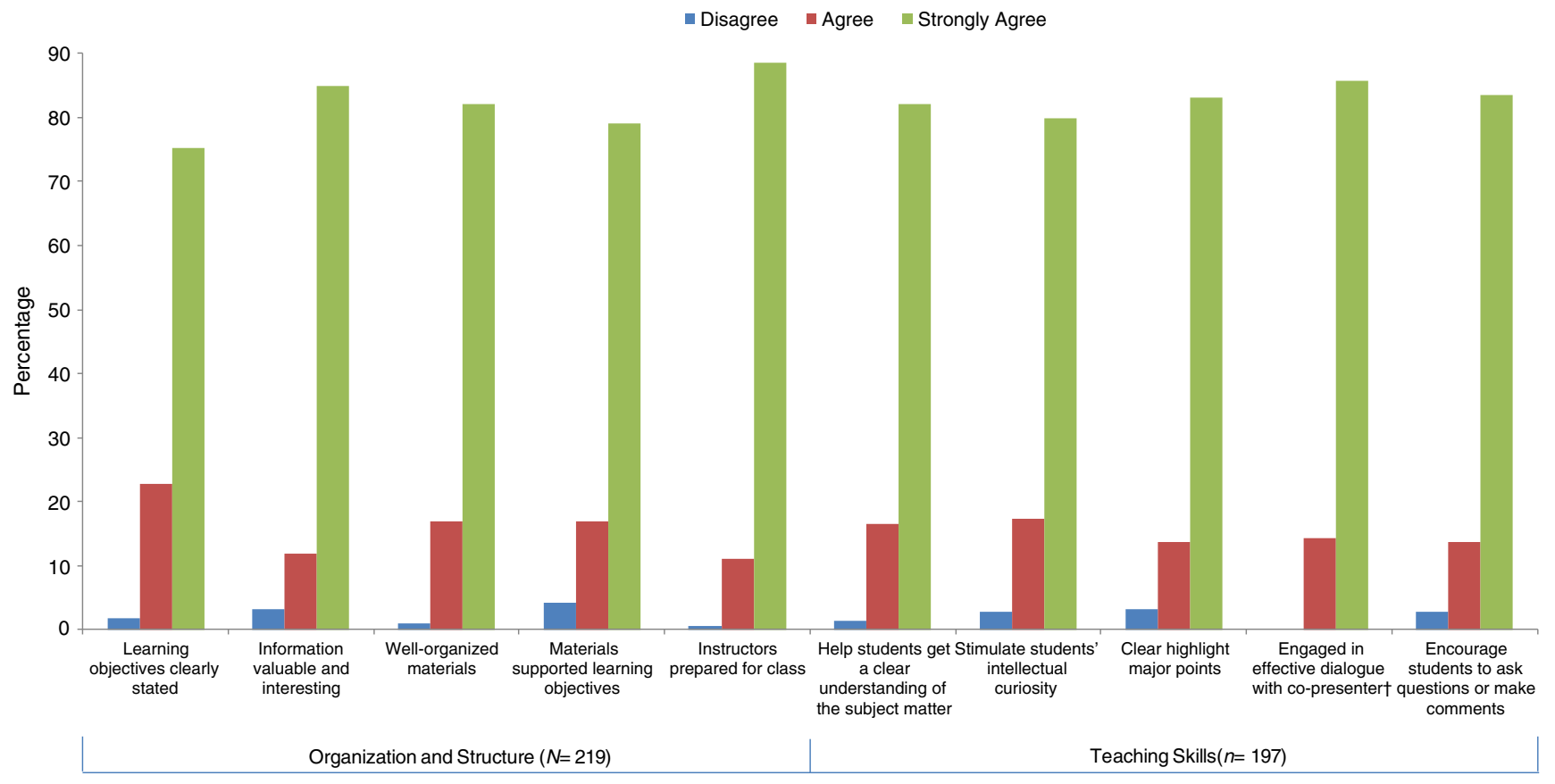

Fig. 2 Students' perceptions of class organization and structure and the teaching skills of presenters for all class sessions. Scores ranged from 1 (strongly disagree) to 4 (strongly agree). The sample size $(N=219)$ refers to the total number of evaluations that were completed by students for all class sessions held over the course of the semester. The sample size for Teaching Skills is 197 because some sessions had only one presenter behavioral exposures that trigger a biological/genetic predisposition for cancer) and the development of corresponding research projects. They also appreciated learning about available datasets with both behavioral and genetic data. Although students regarded some themes about genetics as slightly advanced and noticeably oriented toward the biological sciences, the combination of broad introductions and more complex approaches to the topics was generally well accepted. Moreover, students suggested incorporating more mental health issues to diversify and strengthen the content of the course.

Overall Logistics Students identified the course organization, two-speaker conference format, and small class size as positive aspects that allowed for more interaction and discussion. The written material given for each class and the support received from the DCPPS administrative staff were both rated as excellent. Students reported being dissatisfied with frequent location changes and agreed that additional class time would have been more beneficial.

End-of-Term Course Evaluations During the last class session, students completed an evaluation survey on the content and implementation of the course. On the instrument, four items were rated on a three-point Likert scale from 1 (never/seldom) to 3 (most of the time/always); four items were answered with "yes" or "no"; and one item was openended (Appendix B). Overall, students expressed satisfaction with the course and the topics covered; however, several identified an overlap in some of the information presented during different sessions, and some noted that lectures could have followed a more logical order. On a positive note, one student reported that participating in the course resulted in the development of new collaborations, as one presenter introduced him to another faculty member who agreed to serve as his co-mentor.

\section{Instructors’ Evaluations}

At the end of each class, instructors completed an openended form evaluating the course in the following areas: range and order of syllabus topics, combination of basic science and behavioral science topics, dual-presenter format, emphasis, teaching strategies, and suggestions of new topics not currently included. Speakers' responses on each category were summarized in Table 1.

Evaluation forms were obtained from ten presenters. They represented seven (64\%) different classes. Overall, the majority of presenters were satisfied with the class format and the opportunity to integrate their expertise with that of a colleague from a complementary academic background. Presenters reported that they enjoyed the small, discussionbased setting, which was more personal than a large research audience. Most agreed that the length of each class session should be expanded and suggested reorganiz- 
ing the topics in a more logical order. One presenter commented, "It is challenging to cover both aspects of the topic plus engage in a discussion within the 55-minute timeframe format."

\section{Discussion}

The development and implementation of the graduate course Biobehavioral Research Methods in Cancer Prevention and Addiction resulted in an innovative and successful approach to introducing junior researchers to the advan- tages and challenges of biobehavioral research. In conjunction with a group of experts in cancer prevention and addictive behaviors, the course directors designed a syllabus that highlighted some of the most important themes in the field and brought together presenters from a variety of disciplines to engage in a transdisciplinary and pioneering approach to graduate-level education. The integration of collaborative teaching, learning, and use of technology distinguished the course and helped establish it as an innovative model for adult education.

Several aspects related to the implementation and evaluation of the course are salient to this discussion. Both

Table 1 Instructor evaluations of course

\begin{tabular}{|c|c|}
\hline Category & Positive comments \\
\hline Range of syllabus topics & $\begin{array}{l}\text { - Reasonable" Probably appropriate if one purpose of } \\
\text { this course is to focus specifically on addiction." Good } \\
\text { topic with much fruitful research to explore }\end{array}$ \\
\hline Order of syllabus topics & - Good- Well organized and designed \\
\hline $\begin{array}{l}\text { Combination of basic } \\
\text { science and behavioral } \\
\text { topics }\end{array}$ & $\begin{array}{l}\text { - Good balance- A good approach and emphasizes the } \\
\text { multidisciplinary nature of cancer prevention.- Class } \\
\text { provided a wide breadth of topics relevant to } \\
\text { biobehavioral research. }\end{array}$ \\
\hline Dual-presenter format & $\begin{array}{l}\text { - I like it because allows a diverse set of topics to be } \\
\text { introduced in a relatively short amount of time." I } \\
\text { enjoyed the presentation from my co-speaker }\end{array}$ \\
\hline
\end{tabular}

Emphasis

Teaching strategies

\begin{abstract}
New methodologies or areas of research not currently included
\end{abstract}

- Liked the smaller group with some amount of interaction.
Areas to improve/recommendations

- Organizational burden of this format seems to be high (more speakers are needed and I noticed some TBA speakers in the syllabus)" There are many more behavioral science topics that could be covered, based on the range of research that the Behavioral Science faculty engages in. The current syllabus may give a somewhat slanted and incomplete view of the broader range of behavioral science problems and issues that cancer prevention research focuses on

- Didn't notice a logical presentation of topics

- Should not necessarily be on the same day, logic is more important." It is challenging to cover both topics plus engage in a discussion within the 55-minute timeframe of class." [Need] More time to cover topics

- Was a challenge in 60 minutes" Perceived as problematic; since there was no chance to get into enough of the material and to address all questions

- Not enough emphasis on the behavior piece at the moment

- Not clear what is required from the students- There is no time for in-class discussion. Consider that afterclass discussions of our lecture actually lasted 30 minutes" My only complaint is the time restriction of 1 hour* Have students background info, and titles of previous presentations= Perhaps a $45 \times 2$ format is better. There will be little to no additional effort for a speaker to present an extra 15 minutes" We could give 15-30 minutes longer so all the questions could be answered more thoroughly.

- "Real time" assessments of outcomes using hand-held devices for phenotypes- A session on behavioral research that is not addiction related, such as psychosocial and survivorship research." The work in sexual dysfunction and rehabilitation. Many of these studies have physiological measures and clinical outcomes of importance, in addition to quality of life, wellness and family issues

- Logistics: Email the presenter on the week of their presentation and confirm location and time
Other
- I enjoyed presenting to your students, they were bright and enthusiastic. I enjoyed the questions and discussions with them. Would be happy to do this again. 
presenters and students expressed overall satisfaction with the content and format of the course. Students were proactive, and instructors expressed a high degree of enthusiasm about participating in this innovative effort. The presentation of topics from a transdisciplinary perspective and the interaction between presenters from biological and behavioral science backgrounds were valuable for all participants since they yielded an increased awareness and knowledge of the transdisciplinary nature of cancer and addiction and of various methodological approaches relevant to prevention research. Classroom arrangement (i.e., roundtable format) facilitated discussion and networking, and materials and administrative staff support were practical and useful. On the other hand, presenters, students, and course directors found confining two presentations and discussion in a 1-h class to be challenging.

\section{Strengths and Limitations}

The most significant strength of this educational initiative was the integration and delivery of the combined expertise of faculty from biological and behavioral sciences in a conceptualization of methodological approaches in cancer prevention and addiction research. The exceptional wealth of expertise and the transdisciplinary research environment of the TMC facilitated both intra- and inter-institutional collaboration and recruitment of the widest available selection of experts representing both the biological and behavioral sciences. Additionally, offering the course as an elective through various institutions increased the probability of gathering individuals of various backgrounds who were interested in cancer prevention and addiction and were thus eager to contribute to the dynamic interactions during the course and to provide appropriate feedback related to its implementation. At least one of the course directors attended each class, acting as liaisons between students and presenters and between the co-presenters. They contributed to the learning environment by initiating invigorating discussion after the presentations. Finally, an additional strength was the opportunity for all the contributors to the implementation of this pilot course (i.e., course directors, presenters, and students) to provide their input through a variety of evaluations at various points through the course of the semester.

Given the innovative nature of this venture, several limitations should be noted as well. First, although a number of relevant themes were included in the syllabus, specific domains were not systematically developed; topics were ordered and presented in an informal arrangement, which may have resulted in some repetition of information. Second, because this was the pilot of a one-credit-hour course, formal learning assessments were not performed, thus limiting the ability to evaluate the students' under- standing and application of the concepts discussed. However, the discussion period at the end of each session, along with the portions of two class sessions devoted to student feedback, provided opportunities for students to engage in active synthesis of what they had learned. Also, students' evaluations were not collected by their disciplines, making it impossible to explore differences of perception based on the students' fields of study or previous experience. Finally, although this course may serve as a model for other institutions interested in developing opportunities for transdisciplinary approaches to cancer education, we are aware that the applicability of this approach might vary in other environments with different or fewer resources.

\section{Recommendations}

Based on the evaluations and reflections of the students, presenters, and course directors, we recommend the following for future implementation of this course:

- Continue promoting the creation of graduate courses that integrate biological and behavioral science perspectives on health-related issues.

- Develop broader domains and organize specific themes within each domain to avoid duplicating information and create a logical sequence of topics. Reducing duplication would also allow for the inclusion of additional topics.

- Encourage in-person meetings among co-presenters before the beginning of the course to officially introduce them and their respective areas of expertise and research and to increase the probability of complementary rather than overlapping presentations.

- Provide additional guidance to invited presenters (e.g., an outline, a presentation template, more linkage between co-presenters) to ensure progression throughout the lectures, that is, start with basic concepts related to high-risk behaviors for developing cancer and progress toward specific examples of research design, implementation, and application.

- Design activities to promote active learning that are easy for lecturers to integrate into their prepared presentations and provide structured active learning exercises during the feedback sessions.

- Expand the class time to 1.5 or $2 \mathrm{~h}$ to integrate the two perspectives more thoroughly, address questions, and encourage discussion.

- Include at the beginning of the course an overview of specific research designs and methodology from transdisciplinary perspectives so subsequent presentations of studies are understood within that framework.

- When feasible, pair junior faculty with more senior faculty to provide students with examples of collabora- 
tion at different levels of expertise and to facilitate networking and modeling among the presenters.

- Integrate both quantitative and qualitative measures for evaluating the course to capture a broad range of strengths and areas for improvement.

- Incorporate a formal assessment of students' understanding of transdisciplinary research methods to systematically measure the increase in understanding. Identify students' educational backgrounds during formal evaluations to compare the course's efficacy and utility for social/behavioral science students and biological science students, to determine whether evaluations of the course vary by student background, and to tailor future implementations of the course accordingly.

- Incorporate other class formats along with the lecturebased class format to facilitate active learning.

\section{Final Thoughts}

This paper reports on the development, implementation, and evaluation of a graduate course designed to integrate biological and behavioral science approaches to cancer prevention and addiction research and to respond to gaps in the education and training of transdisciplinary researchers. Though the course was challenging for both presenters and students - and for the host institution, in that it called for a new model of teaching-meeting that challenge can result in important gains for all involved. If public health professionals are to approach cancer prevention and the remediation of addictive behaviors in innovative ways that pursue the integration of knowledge and practice, then public health training must also be developed by thinking outside the box. By implementing novel approaches today, we can help junior researchers better prepare for emerging problems in research and, ultimately, contribute to a greater understanding of the complex interplay between behavior and health. We believe we have made successful strides toward this end, as one student wrote, "I really enjoyed the course and would consider retaking the class in the future."

Acknowledgments The authors would like to acknowledge Tuan T. Nguyen for helping to organize and present the evaluation data. They would also like to thank Dr. Peter Abotchie for his contributions as well. This work is supported in part by awards from the National Institutes of Health/National Cancer Institute (NIH/NCI): MD Anderson Cancer Center Support Grant, CA016672; MD Anderson Education Program in Cancer Prevention, R25T CA57730 (PI: S Chang); and Cancer Prevention Education: Short-term Research Experiences, R25E CA56452 (PI: S Chang). Sarmira Kamrudin is a trainee supported by an award from the NIH/NCI, Behavioral Science
Education-Cancer Prevention and Control (CA057712, PI: PD Mullen). The content is solely the responsibility of the authors and does not necessarily represent the official views of the National Cancer Institute or the National Institutes of Health.

\section{References}

1. Institute of Medicine (2001) Health and behavior: the interplay of biological, behavioral, and societal influences. National Academy Press, Washington, DC

2. Institute of Medicine (1982) Health and behavior: frontiers of research in the biobehavioral sciences. National Academy Press, Washington, DC

3. Kahn RL (1993) An experiment in scientific organization. A MacArthur Foundation Occasional Paper. The John D. and Catherine T. MacArthur Foundation, Program in Mental Health and Human Development, Chicago, IL

4. Nass SJ, Stillman B (eds) (2003) Large-scale biomedical science: exploring strategies for future research. The National Academies Press, Washington, DC

5. The National Academies (2003) The National Academies Keck Futures Initiative. http://www.keckfutures.org. Accessed 16 Feb 2011

6. Stokols D, Hall KL, Taylor BK, Moser RP (2008) The science of team science: overview of the field and introduction to the supplement. Am J Prev Med 35(2S):S77-S89

7. Stokols D, Shalini M, Moser RP, Hall KL, Taylor BK (2008) The ecology of team science: understanding contextual influences on transdisciplinary collaboration. Am J Prev Med 35 (2S):S96-S115

8. Wuchty S, Jones BF, Uzzi B (2007) The increasing dominance of teams in production of knowledge. Science 316(5827):10361039. doi:10.1126/science. 1136099

9. Mabry PL, Olster DH, Morgan GD, Abrams DB (2008) Interdisciplinarity and systems science to improve population health: a view from the NIH office of behavioral and social sciences research. Am J Prev Med 35(2S):S211-S224

10. Frank K, Rosenfield PL (2008) Toward transdisciplinary research: historical and contemporary perspectives. Am J Prev Med 35(2S): S225-S233

11. Abrams DB, Leslie FM, Mermelstein R, Kobus K, Clayton RR (2003) Transdisciplinary tobacco use research. Nicotine \& Tobacco Res 5(1S):S5-S10

12. Weingart P, Stehr N (eds) (2000) Practising interdisciplinarity. University of Toronto Press, Toronto, Canada

13. Younglove-Webb J, Gray B, Abdalla CW, Thurow AP (1999) The dynamics of multidisciplinary research teams in academia. Rev High Educ 22(4):425-440

14. Rhoten D, Parker A (2004) Risks and rewards of an interdisciplinary research path. Science 306(5704):2046. doi:10.1126/science.1103628

15. Croyle RT (2008) The National Cancer Institute's transdisciplinary centers initiatives and the need for building a science of team science. Am J Prev Med 35(2):90

16. Hall KL, Stokols D, Moser RP, Taylor BK, Thornquist MD, Nebeling LC, Ehret CC, Barnett MJ, McTiernan A, Berger NA, Goran MI, Jeffery RW (2008) The collaboration readiness of transdisciplinary research teams and centers: findings from the National Cancer Institute's TREC Year-One evaluation study. Am J Prev Med 35(2):S161-S172

17. Hiatt RA, Breen N (2008) The social determinants of cancer: a challenge for transdisciplinary science. Am J Prev Med 35(2): S141-S150 